\title{
Study of control and stability of diesel engine operation using fractional calculus
}

\author{
Leonard-Iulian Cucu ${ }^{1}$ and Ion Copae ${ }^{2, *}$ \\ ${ }^{1}$ SAR City Insurance, 12-14 Father Galeriu Str., Bucharest, Romania. \\ 2 Department of Military Vehicles and Transportation, Military Technical Academy "Ferdinand I", 39-49 George Cosbuc \\ Blvd., Bucharest, Romania.
}

Global Journal of Engineering and Technology Advances, 2021, 07(01), 113-123

Publication history: Received on 12 March 2021; revised on 17 April 2021; accepted on 20 April 2021

Article DOI: https://doi.org/10.30574/gjeta.2021.7.1.0059

\begin{abstract}
The paper presents aspects related to the operation of an electronically controlled diesel engine that equips two cars. Some data related to 100 experimental tests for each car are presented. Some elements related to the electronic control and stability of the Diesel engine are presented by using the fractional calculation to generalize the study.
\end{abstract}

Keywords: Diesel engine; Fractional calculus; Fractional differential equations; Electronic control; Engine stability.

\section{Introduction}

Current Diesel engines are equipped with various electronic control systems, designed to ensure the required performance in terms of dynamism, economy, compliance with anti-pollution rules, all under conditions of various restrictions.

In addition, electronic control must also provide some of its specific requirements, the most important of which are: low response time, override and stationary error; large amplitude and phase stability reserves; reduced sensitivity to the action of functional, constructive and operational factors; robustness of performance and stability of engine operation; minimizing as much as possible the influence of disturbances on engine performance and stability; mitigating the negative effects and ensuring the performances imposed in the presence of nonlinearities of different nature; optimizing engine performance under restrictive conditions etc. $[4,5,11,16]$.

\section{Stability of a fractional system}

Fractional calculus is a generalization of the frequently used classical calculus in which derivatives and integrals are of the whole order. Being a generalization, it is therefore expected that fractional mathematical models describe more accurately the dynamics of systems and processes than whole-order models, which is confirmed in practice [1].

At present, fractional calculation is used in the study of electrical circuits, in signal processing, in electrochemical processes, in bioengineering, in economic processes, in finance, in the dynamics of nuclear reactions, in systems theory, in automatic control, in medicine, in earthquake dynamics, in various branches of engineering etc. [6, 14].

In mechanics, fractional calculus is used in oscillations and vibrations, in the diagnosis of mechanisms and machines, in nanotechnology, in fluid diffusion processes in porous materials, in the dynamics and control of robots, in the control of the rolling motion of railway vehicles, in fluid mechanics, in the dynamics of flexible transmissions, in the propagation of waves in porous materials etc. [13].

In the automotive field, fractional calculation is used in the control of longitudinal and lateral dynamics, in the control of rollover motion, in the control of cruising speed, in the control of the ABS system, in the control of steering, in the control of active suspension, in the modeling and control of injection with common-rail, in modeling the dynamics of

\footnotetext{
* Corresponding author: Ion Copae

Military Technical Academy "Ferdinand I", Bucharest, Romania.

Copyright (C) 2021 Author(s) retain the copyright of this article. This article is published under the terms of the Creative Commons Attribution Liscense 4.0.
} 
the public transport network, in modeling the impact on the reconstruction of road accidents, in designing the actuators of electronic control systems, in controlling the operation of the car engine, in electronic control of the throttle dynamics etc.

The stability of a fractional system is studied according to its type and according to its mathematical description; only autonomous linear systems are covered below [7].

\subsection{Mathematical description in the form of state space.}

A continuous autonomous fractional linear system is described as:

$\frac{\mathrm{d}^{\overline{\boldsymbol{\alpha}}} \mathbf{x}(t)}{\mathrm{d} t^{\overline{\boldsymbol{\alpha}}}}=\mathbf{A x}(t) ; \mathbf{x}_{0}=\mathbf{x}(0) \Leftrightarrow D^{\overline{\boldsymbol{\alpha}}} \mathbf{x}(t)=\mathbf{A} \mathbf{x}(t) ; \mathbf{x}_{0}=\mathbf{x}(0)$

where the state vector is $\mathbf{x}(t)=\left[\begin{array}{llll}x_{1}(t) & x_{2}(t) & \ldots & x_{n}(t)\end{array}\right]^{T} \in \square^{n}$, and the vector of the fractional order of each equation is $\overline{\boldsymbol{\alpha}}=\left[\begin{array}{llll}\alpha_{1} & \alpha_{2} & \ldots & \alpha_{n}\end{array}\right]^{T}$.

In particular, if $\alpha_{1}=\alpha_{2}=\ldots=\alpha_{n}=\alpha$, then the system (1) becomes:

$\frac{\mathrm{d}^{\alpha} \mathbf{x}(t)}{\mathrm{d} t^{\alpha}}=\mathbf{A x}(t) ; \mathbf{x}_{0}=\mathbf{x}(0) \Leftrightarrow D^{\alpha} \mathbf{x}(t)=\mathbf{A x}(t) ; \mathbf{x}_{0}=\mathbf{x}(0)$

In fractional differential equations (1) and (2) the form for the fractional derivative of the order $\alpha$ :

$\frac{\mathrm{d}^{\alpha} \mathbf{x}(t)}{\mathrm{d} t^{\alpha}} \equiv D^{\alpha} \mathbf{x}(t)$

The system (1), in which the fractional order of the differential equations is different, is called the incommensurable system. The system (2), in which the fractional order of the differential equations is the same, is called the commensurable system.

Regarding stability, according to Matignon's theorem it results, for example for the commensurable autonomous system (2):

- the system is asymptotic/strictly stable if and only if the condition is met:

$$
\left|\arg \left(\lambda_{i}(\mathbf{A})\right)\right|>\alpha \frac{\pi}{2}
$$

where $\lambda_{i}(\mathrm{i}=1,2, \ldots, \mathrm{n})$ are the eigenvalues of the matrix $\mathrm{A}$.

- at the stability limit, if the eigenvalues of the matrix A satisfy the condition:

$\left|\arg \left(\lambda_{i}(\mathbf{A})\right)\right|=\alpha \frac{\pi}{2}$

are simple eigenvalues (multiplicity order 1 ).

- the system is unstable if the condition is met:

$\left|\arg \left(\lambda_{i}(\mathbf{A})\right)\right|<\alpha \frac{\pi}{2}$

The graphical representation of these statements is presented in figure 1. The classic case, of a continuous system of whole order, is represented in figure $1 \mathrm{~b}$ for $\alpha=1$; as can be seen, an integer system is strictly stable if all the roots of 
the characteristic equation are in the left complex half-plane and is at the limit of stability if the roots are on the vertical axis.

It also follows from figure 1 that the highest range of stability is for $0<0<1$ (figure $1 \mathrm{a}$ ), and the smallest for $1<\alpha<2$ (figure 1c).

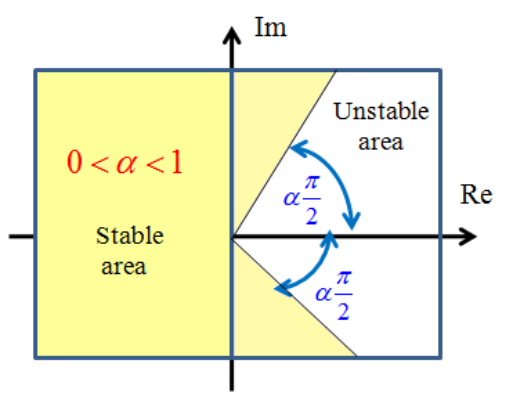

a)

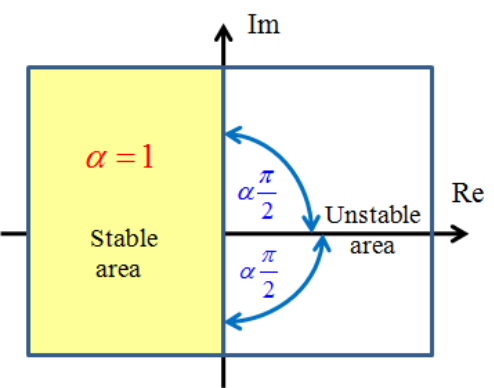

b)

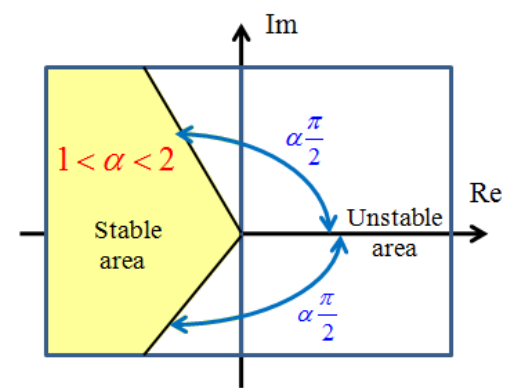

c)

Figure 1 Stability of a dynamic system

\subsection{Mathematical description in the form of a fractional differential equation}

If the system is described by a fractional differential equation, either the mathematical description is established in the state space (as in the previous case), or this equation is directly targeted. In the latter case it is taken into account that the main area of the Riemann surface, which ensures the stability of a system, is defined by:

$-\pi<\arg (s)<\pi$

where s represents the argument of the Laplace transform, which is a complex variable.

Figure 2a shows a Riemann surface with two areas, and in figure $2 \mathrm{~b}$ one with three areas, the main one being the first lower area.

Stability of fractional systems: Riemann surfaces for $s^{1 / 2}$ and $s^{1 / 3}$, respectively with two and three areas

a) Surface with 2 areas, for $\mathrm{s}^{1 / 2}$

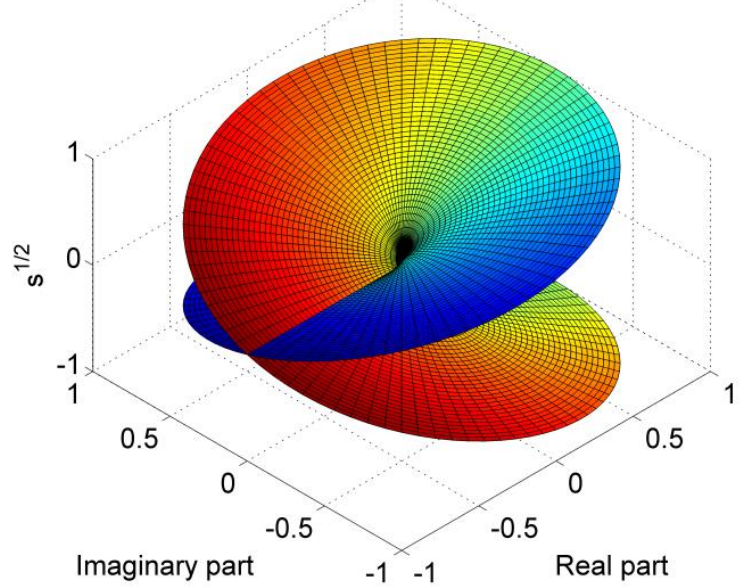

b) Surface with 3 areas, for $s^{1 / 3}$

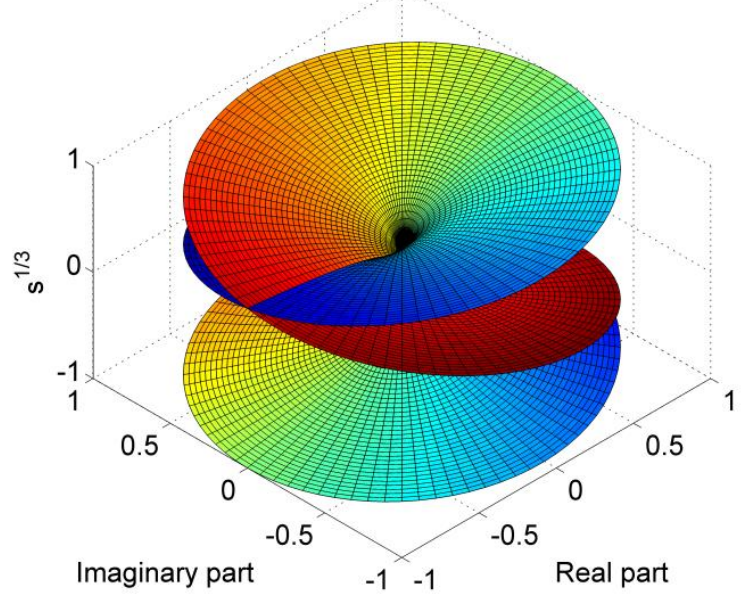

Figure 2 Riemann surfaces with two and three areas

A Riemann surface is obtained by entering the complex variable:

$$
w=s^{\alpha}
$$

with $\alpha$ fractional number; as a result, the corresponding domain for w is:

$-\alpha \pi<\arg (w)<\alpha \pi$ 
Denoting $\alpha=1 / m$, then the stability condition (main area of the Riemann surface) becomes in the plane w:

$-\frac{\pi}{m}<\arg (w)<\frac{\pi}{m}$

An example is now aimed at the fractional differential equation:

$0.8 D^{2.2} y(t)+0.5 D^{0.9} y(t)+y(t)=u(t)$

The characteristic equation is:

$P(s)=0.8 s^{2.2}+0.5 s^{0.9}+1=0$

or:

$$
P(s)=0.8 s^{22 / 10}+0.5 s^{9 / 10}+1=0
$$

It turns out that in this case $\mathrm{m}=10, w=s^{1 / 10}$, and the corresponding equation is:

$$
P(w)=0.8 w^{22}+0.5 w^{9}+1=0
$$

which has 22 roots. Of these, the smallest argument is the roots (command "roots" from Matlab):

$$
w_{1 ; 2}=1.0045 \pm 0.1684 i \Rightarrow\left|\arg \left(w_{1 ; 2}\right)\right|=0.1661
$$

The roots are in the first area of the Riemann surface if condition (10) is met, in this case:

$$
-\frac{\pi}{10}<0.1661<\frac{\pi}{10}
$$

which is true. It follows that the system described by the fractional differential equation (11) is stable.

Stability is also confirmed in the complex plane of the variable s. Thus, the roots result from equation (12) $s_{1 ; 2}=-0.10841 \pm 1.19699 i$, complex-conjugated with the real negative part (command "solve" in Maple).

The Riemann condition (7) is checked (Matlab "angle" command):

$$
-\pi<\left|\arg \left(s_{1 ; 2}\right)\right|=1.661<\pi
$$

and thus the stability of the system described by the differential equation (11) is confirmed.

\section{Experimental research}

The experiments were carried out with a Ford Focus car (denoted FF) and a Volkswagen Touareg II 3.0 V6 TDI (denoted VW), both equipped with a turbocharged diesel engine and a common-rail fuel system. The acquisition of the functional variables was carried out using the FoCOM interface and software of the Ford company, respectively the VCDS application developed by the Ross-Tech company, which is the specialized diagnostic software for the Volkswagen group.

From the data obtained, 100 more significant experimental samples were retained for the purposes pursued (marked F1-F100, respectively V1-V100), which mark the frequent load and speed regimes during the operation of cars.

Thus, figure 3 shows, in the case of the VW car, the instantaneous values of the engine torque Me, the engine power Pe, the position of the accelerator pedal $\mathrm{p}$ (often considered as the engine load) and the engine speed $\mathrm{n}$, the graphs showing the minimum values, averages and maximums of the respective variables. 
Figure 4 shows, in the case of the FF car, the instantaneous, minimum, average and maximum values on the set of tests, the engine torque Me and the engine power Pe.
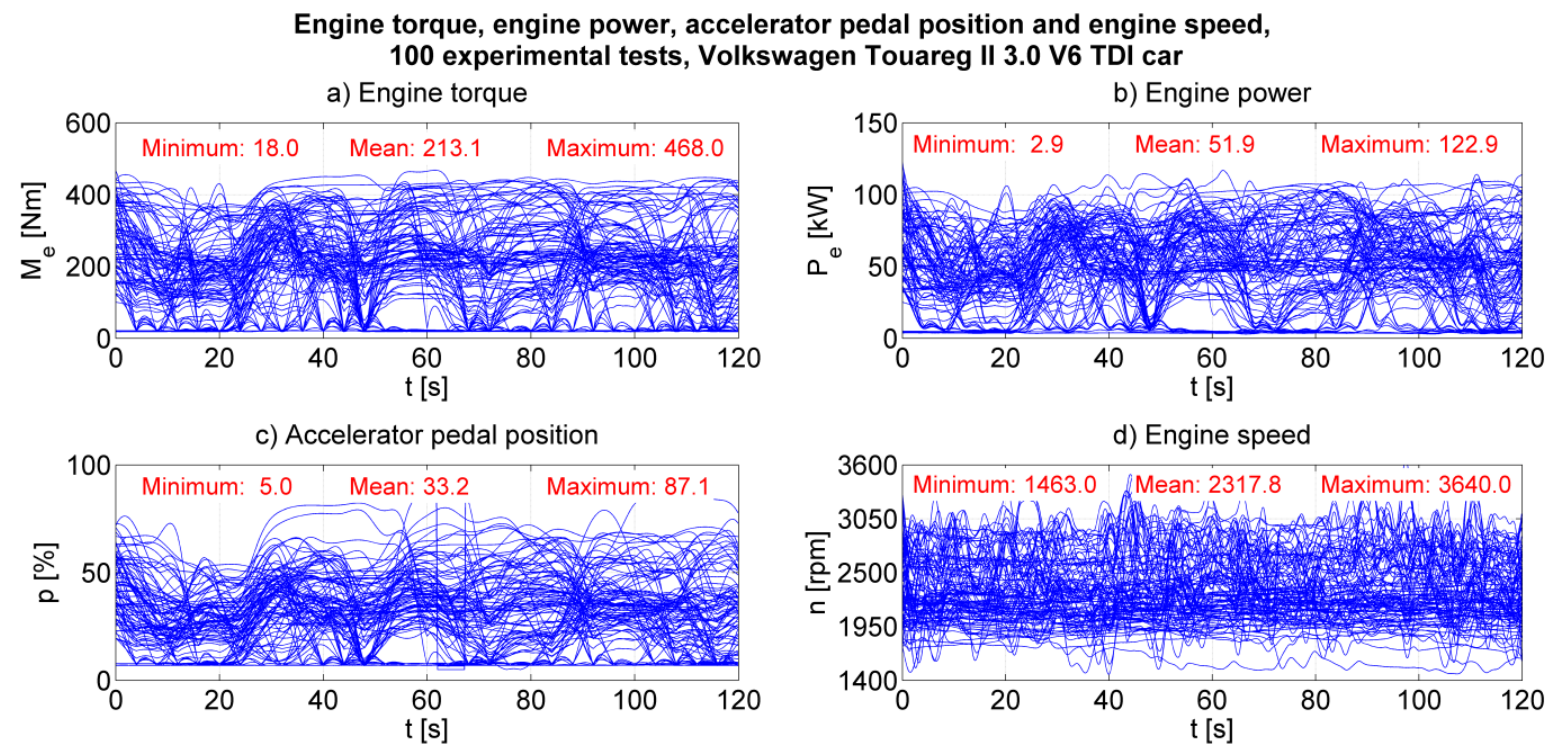

Figure 3 Engine torque, engine power, engine load and engine speed, VW car
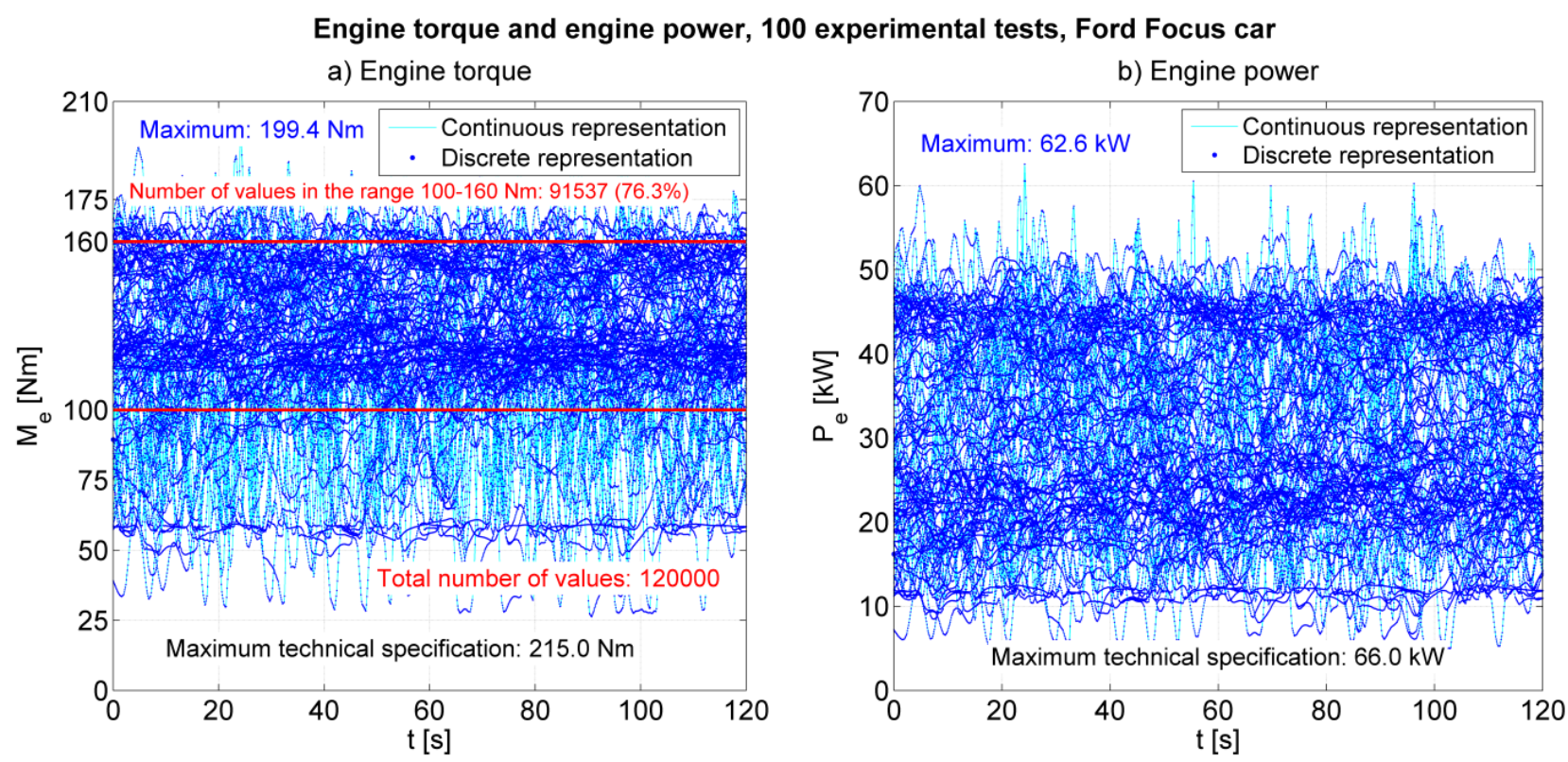

Figure 4 Engine torque and engine power, FF car

Figure 3a shows that during the experiments, the engine torque varied in the range of 18.0-468 Nm, the average of all tests being $213.1 \mathrm{Nm}$. The graph in figure 3b shows that the engine power varied in the range of $2.8-122.9 \mathrm{~kW}$, the average for all tests being $51.9 \mathrm{~kW}$. Figure 1c shows that the engine load varied in the range of $5.0-87.1 \%$, the average for all tests being $33.2 \%$. Figure $1 \mathrm{~d}$ shows that the engine speed varied between $1463.0-3640.0 \mathrm{rpm}$, the average of all tests being $2317.8 \mathrm{rpm}$.

In figure 4 the two variables are presented in continuous representation and in discrete representation, the last one, the real one, allowing the establishment of the intervals with the majority of the values. As a result, from figure $4 \mathrm{a}$ it results that $76.3 \%$ of the total values of the engine torque are in the range $100-160 \mathrm{Nm}$.

Figure 4 also shows the maximum values in the technical specification of engine torque and engine power, of $215 \mathrm{Nm}$ and $66 \mathrm{~kW}$, respectively; from experiments the maximum values of $199.4 \mathrm{Nm}$ and $62.6 \mathrm{~kW}$ respectively were obtained. 


\section{Modelling of operation, control and engine stability}

Next, these three aspects are also approached on the basis of fractional calculus, which is a generalization of classical calculus. In this sense, it results that in the general case the mathematical model of the operation is a differential equation of fractional order, the control benefits from algorithms in the fractional field, and the stability of the operation is studied as previously presented $[8,9,10,12,15]$.

Thus, for example, the electronic control may use a fractional PID controller, which in this case becomes a $P I^{\lambda} D^{\mu}$ controller, as shown in figure 5.

For a fractional control (of non-integer order), the transfer function becomes:

$C(s)=\frac{u(s)}{e(s)}=k_{P}+\frac{k_{i}}{s^{\lambda}}+k_{d} s^{\mu}=\frac{k_{d} s^{\lambda+\mu}+k_{p} s^{\lambda}+k_{i}}{s^{\lambda}}$

with the diagram in figure $5 \mathrm{~b}$.

In these expressions were noted: kp - static transfer coefficient for the proportional element P; ki - static transfer coefficient for the integrating element I; kd - static transfer coefficient for the derivative element D.

If $\lambda=\mu=1$, then there is a classic PID controller [3]. Therefore, the fractional controller $P I^{\lambda} D^{\mu}$ is a generalization, the whole PID controller being a particular case of it (figure $5 \mathrm{a}$ ).

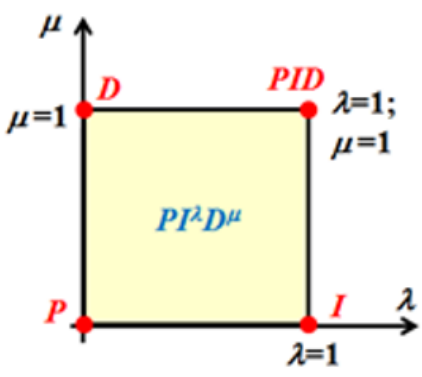

a)

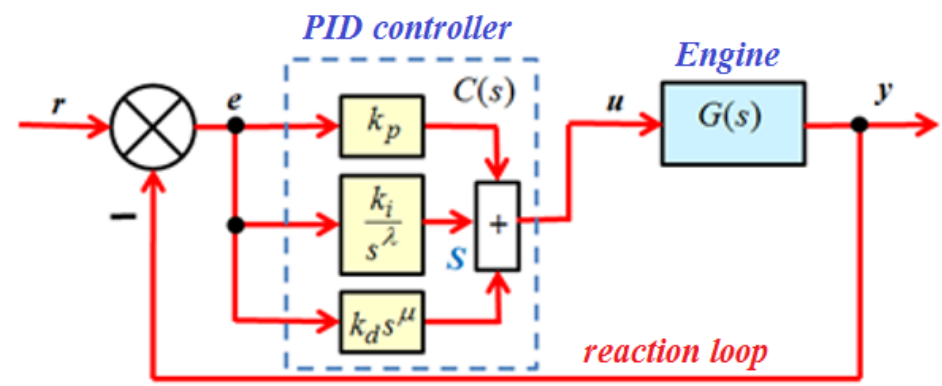

b)

Figure 5 Diagram of the $P I^{\lambda} D^{\mu}$ type controller

Figure 5a shows that the fractional controller is usually adopted $0<\lambda<1,0<\mu<1$, which ensures the highest range of stability, as previously seen in figure 1 ; for dynamic reasons, $\lambda$ and $\mu$ can also be easily adopted as super-unitary. As an example, figure 6 shows the results of establishing the fractional model that allows the calculation of the engine torque $\mathrm{M}_{\mathrm{e}}$ depending on the position of the accelerator pedal $\mathrm{p}$ in the experimental test F65 of the Ford Focus car.

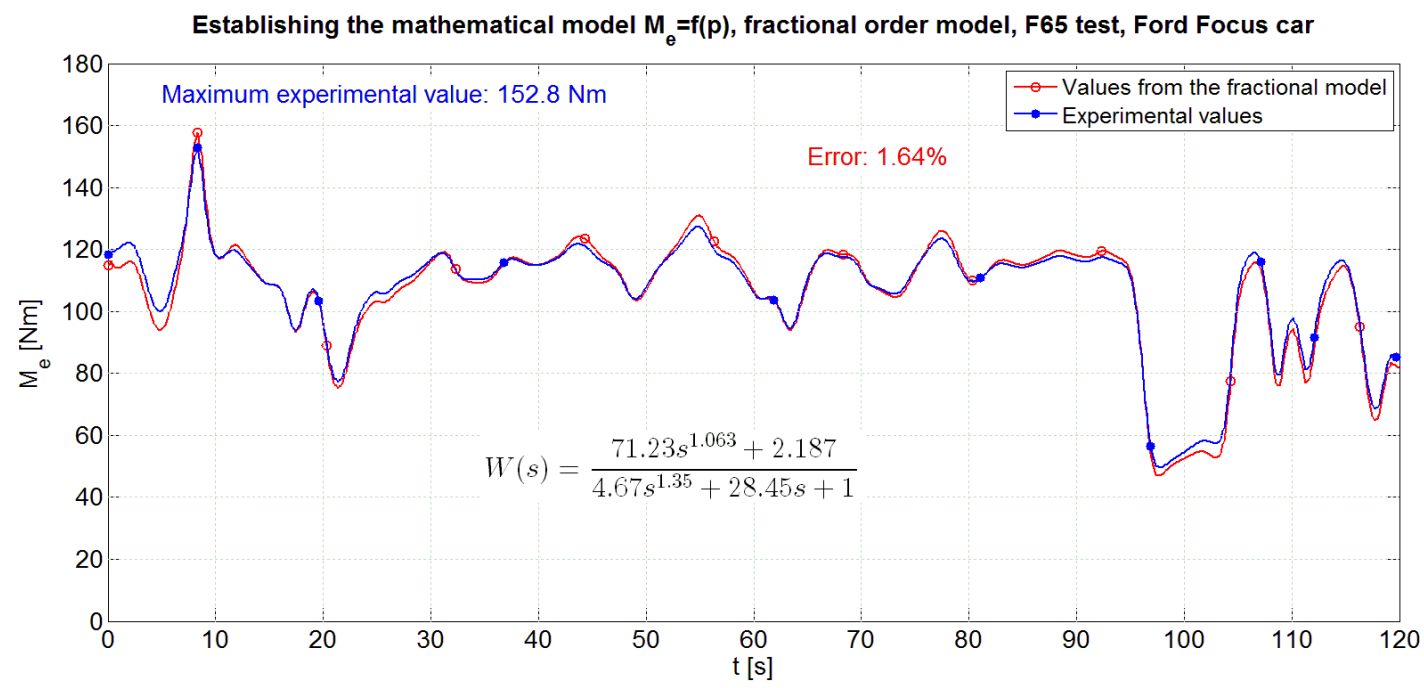

Figure 6 Fractional mathematical model Me=f(p), F65 test, FF car 
The graph shows the transfer function:

$$
W(s)=\frac{M_{e}(s)}{p(s)}=\frac{71.23 s^{1.063}+2.187}{4.67 s^{1.35}+28.45 s+1}
$$

This results in the mathematical model sought:

$$
4.67 D^{1.35} M_{e}(t)+28.45 D^{1.00} M_{e}(t)+M_{e}(t)=71.23 D^{1.063} p(t)+2.187 p(t)
$$

which represents a fractional differential equation of the order of 1.35 .

As shown in Figure 6, the modeling error is $1.64 \%$, an acceptable value.

The following is to establish a $P I^{\lambda} D^{\mu}$ controller for this example from the F65 experimental test of the Ford Focus car. Thus, for comparison, figure $7 \mathrm{~b}$ shows the transfer function $\mathrm{C}(\mathrm{s})$ of a PID controller and figure $7 \mathrm{c}$ of the transfer function $\mathrm{C}(\mathrm{s})$ of a $P I^{\lambda} D^{\mu}$ controller.

Figure 7a shows the dynamic step-type response of the closed-loop system without controller, in figure 7b of the closedloop system with PID controller, and in figure $7 \mathrm{c}$ of the closed-loop system with $P I^{\lambda} D^{\mu}$ controller.

As shown in figure 7 , the response time and system override with $P I^{\lambda} D^{\mu}$ controller are the smallest $\left(\mathrm{t}_{\mathrm{r}}=4.62 \mathrm{~s}\right.$ and $\sigma=$ $0 \%)$.

Also, the longest rise time $t_{c}$ also exists for the $P I^{\lambda} D^{\mu}$ controller, which is an advantage because, as is well known, too short a rise time indicates high system loads.
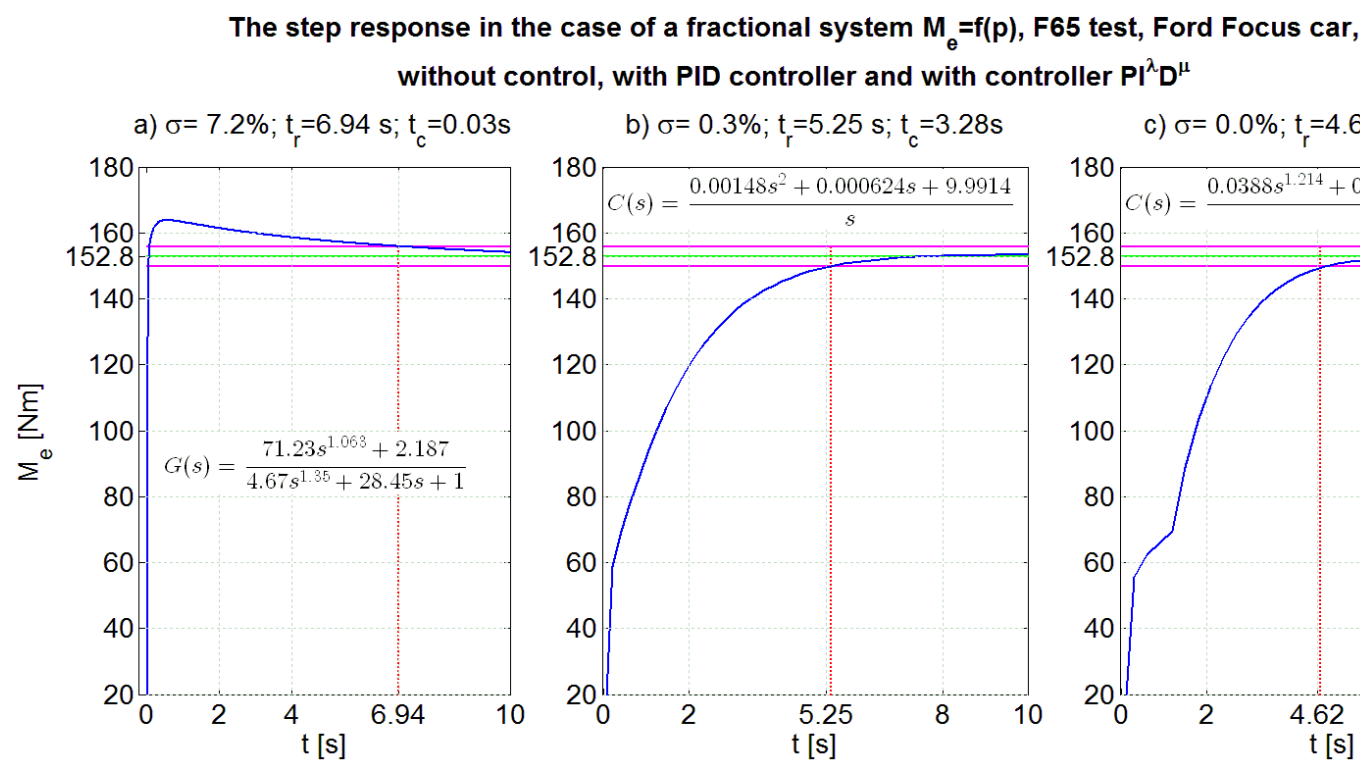

Figure 7 Engine step response in three situations, F65 test, FF car

For example, figure $7 \mathrm{a}$ shows a too sudden increase of the engine torque, with the highest value, the rise time $t_{c}$ being the longest.

The step value of $152.8 \mathrm{Nm}$ used in the calculations corresponds to the maximum moment from test F65, as seen in figure 6.

Therefore, in this case the $P I^{\lambda} D^{\mu}$ fractional controller ensures the best dynamic engine performance. Comparing the relations (17) with the expression $\mathrm{C}(\mathrm{s})$ in figure $7 \mathrm{c}$, results the parameters of the $P I^{\lambda} D^{\mu}$ controller established by the Ziegler-Nichols algorithm:

$k_{p}=0.2168 ; k_{i}=9.1994 ; k_{d}=0.0388 ; \lambda=1.029 ; \mu=0.185$

From figure 7 it should also be noted that in all three cases the stability of the diesel engine is ensured, because the curves of the transient process tend towards a finite value cumulatively over time.

Stability can also be verified as presented above. For example, the characteristic equation results from expression (19): 
$P(s)=4.67 s^{1.35}+28.45 s+1=0$

which has the solutions $s_{1 ; 2}=-0.03427 \pm 0.00149 i$, complex-conjugated with the real negative part ("solve" command from Maple) and therefore the stability of the motor is checked. This is also confirmed by the fact that the Riemann condition (7) is met, for example by using the "angle" command in Matlab:

$$
-\pi<\left|\arg \left(s_{1 ; 2}\right)\right|=3.098<\pi
$$

As mentioned, the previous example is the general case, when the mathematical model is fractional, but the controller is fractional.

The following is a particular case, when the mathematical model is fractional and the controller is in the integer field. An example of this is the case of optimizing engine fuel consumption by using an LQR (Linear Quadratic Regulator) algorithm that is described mathematically throughout.

This control algorithm allows the establishment of a linear controller consisting of a Kalman estimator as well as an optimal controller, both according to state, using a square type optimization criterion.

The state space estimator is applied to the system:

$\left\{\begin{array}{l}x^{\prime}(t)=A x(t)+B u(t)+G w(t) \\ y(t)=C x(t)+D u(t)+H w(t) \\ y_{v}(t)=y(t)+v(t)\end{array}\right.$

and allows the estimation of the state $\mathrm{x}$ when the control $\mathrm{u}$ is known, as well as the noise of the sensor $\mathrm{v}$ and the noise of the model $\mathrm{w}$, as in figure 8.

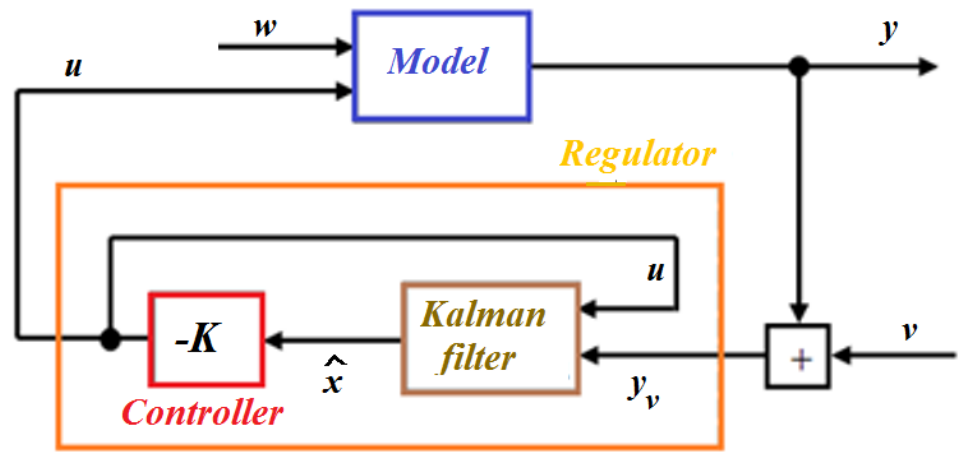

Figure 8 Scheme of optimal linear control LQR

The equations of the estimator (Kalman filter) are:

$$
\left\{\begin{array}{l}
\hat{x}^{\prime}=A \hat{x}+B u+L\left(y_{v}-C \hat{x}-D u\right) \\
{\left[\begin{array}{l}
\hat{y} \\
\hat{x}
\end{array}\right]=\left[\begin{array}{l}
C \\
I
\end{array}\right] \hat{x}+\left[\begin{array}{l}
D \\
O
\end{array}\right] u}
\end{array}\right.
$$

the matrix L being established from Riccati's equation.

The optimal command is:

$u(t)=-K x(t)$

where K results from Riccati's equation.

The following is an example of applying the optimal linear control LQR to the experimental V24 test of the Volkswagen Touareg II 3.0 V6 TDI. In this sense, the aim is to optimize fuel consumption, respectively minimize it provided that the 
dynamic performance (here through engine power) decreases by no more than $4 \%$, this being an additional restriction for the algorithm. Thus, figure 9 shows the deduction of the mathematical model that provides the values of the hourly fuel consumption $\mathrm{C}_{\mathrm{h}}$ as a function of the position of the accelerator pedal p, through the transfer function G(s) [2, 17]. As a result, figure 9 shows the fractional differential equation of the order of 1.2:

$$
2.72 D^{1.2} C_{h}(t)+0.45 D^{0.85} C_{h}(t)+C_{h}(t)=20.4 D^{0.445} p(t)+0.106
$$

with an acceptable modeling error of $0.45 \%$, expression (27) being the mathematical model of engine operation in the V24 test.

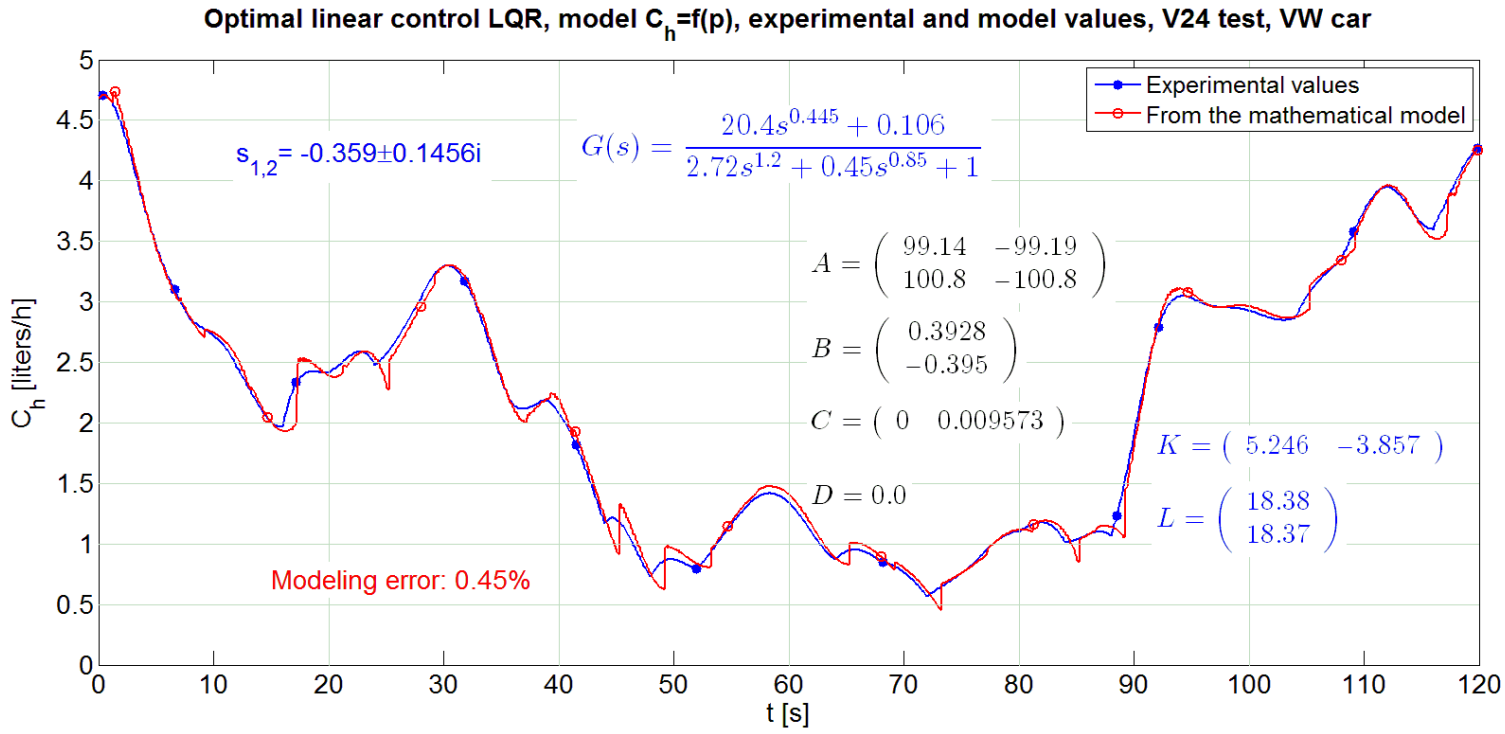

Figure 9 Mathematical model of engine operation related to LQR control, VW car

Figure 9 also shows the values of the quantities of the LQR control algorithm expressed by the relations (24) - (26). In addition, from the $s_{1,2}$ values of the roots of the characteristic equation (which are complex-conjugated with the real negative part), it results that the stability of the Diesel engine operation is ensured.

Figure 10 shows the results of applying the optimal control algorithm. The graphs show that by applying this control, the average test value of hourly fuel consumption decreased by $8.93 \%$, in which case the power decreased by $3.84 \%$, the latter being lower than the required value of $4 \%$.
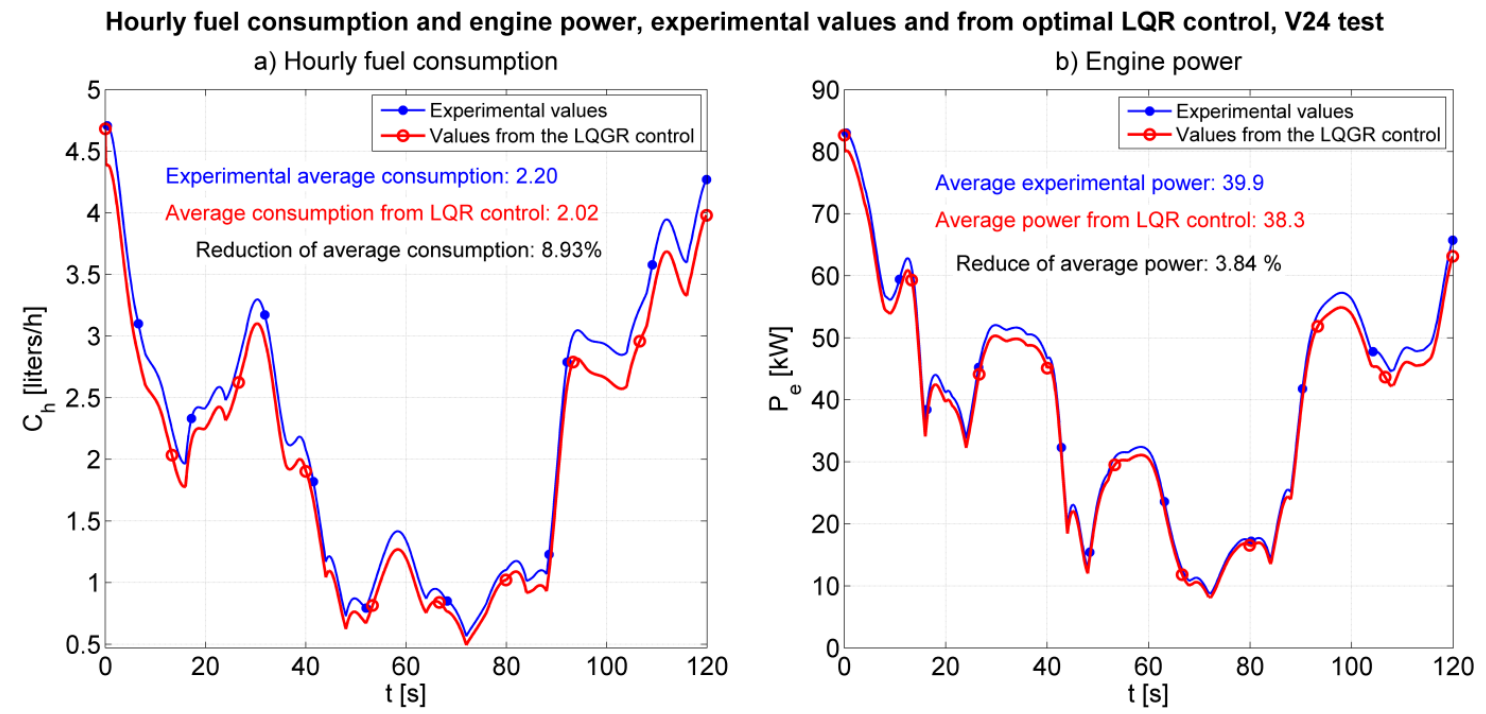

Figure 10 Results obtained by applying the optimal linear control LQR, VW car 


\section{Conclusion}

Fractional calculus has the advantage that it allows the study of the operation, stability and control of the diesel engine in a generalized way, the classical study being a particular case. In addition, operation modeling and electronic control benefit from algorithms that ensure greater accuracy compared to the classical study.

Based on the data purchased from the on-board computer, the operation of the engine at different loads and speeds can be analyzed. Experiments have shown that the engine runs predominantly at partial loads and very little at full load. Also, based on the experimental data can be established customized or generalized mathematical models, of integer or fractional order, which can be used to control the engine and to optimize its performance.

\section{Compliance with ethical standards}

\section{Acknowledgments}

$-$

\section{Disclosure of conflict of interest}

$-$

\section{References}

[1] Aoun M. Numerical simulations of fractional systems: an overview of existing methods and improvements. Nonlinear Dynamics, No. 39, pag. 117-131, 2004, https://link.springer.com/article/10.1007/s11071-004-3750$\mathrm{Z}$

[2] Barothi L., Voicu D., Stoica R.-M., Singureanu M. Recording of parameters characteristic to engine and vehicle in order to validate a simulation model for fuel consumption. 5th International Scientific Conference SEA-CONF 2019, 17-18 May 2019, Mircea cel Batran Naval Academy, Constanta, Romania, IOP Conf. Series: Journal of Physics: Conf. Series 1297 (2019) 012030 IOP Publishing, doi:10.1088/1742-6596/1297/1/012030

[3] Barothi L., Stoica R.-M., Voicu D., Singureanu M. Simulation and comparative analysis of pollutant emissions before and after PID control of engine functioning. Ingineria Automobilului, nr. 56, sep. 2020, pg. 19-23, ISSN 1842-4074

[4] Chauvin J. Modeling and control of a Diesel HCCI engine. Institut Francais du Petrol, 2017. Fifth IFAC Symposium on Advances in Automotive Control, Seascape Resort: United States (2007)". DOI: 10.3182/20070820-3-US2918.00064

[5] Cheng Li. Transient modeling of a Diesel engine and air-path control. Doctoral Thesis, University of Sussex, 2015. http://sro.sussex.ac.uk/id/eprint/55340/

[6] Debnath L., Recent applications of fractional calculus to science and engineering. January 2003. International Journal of Mathematics and Mathematical Sciences 2003(54).DOI: 10.1155/S0161171203301486.

[7] Diethelm K. The Analysis of Fractional Differential Equations. Springer-Verlag, Berlin, 2010.

[8] Dong T. Model-based state feedback controller design for a turbocharged Diesel engine with an EGR system. Energies 2015, 8, 5018-5039; doi:10.3390/en8065018

[9] Hartley T. and Lorenzo C. Fractional system identification: an approach using continuous order-distributions. University of Akron, Ohio, 1999. Report NASA/TM- 1999-209640. https://ntrs.nasa.gov/citations/20000002833

[10] Huang M. Toward Real-Time Automotive Model Predictive Control: A Perspective from a Diesel Air Path Control Development. 2018, DOI: 10.23919/ACC.2018.8431407

[11] Isermann R. Engine modeling and control. Springer-Verlag Berlin Heidelberg, 2014. https://link.springer.com/book/10.1007/978-3-642-39934-3

[12] Kuznetsov A.G. A mathematical model of a Diesel engine for simulation modeling of the control system. Global Journal of Pure and Applied Mathematics, vol.12, nr.1, pp 213-228, 2016.

[13] Ortigueira M.D. Fractional Calculus for Scientists and Engineers. Springer Heidelberg, 2011. 
[14] Petras I. Fractional-Order Nonlinear Systems. Springer, New York, 2011

[15] Podlubny I. Fractional-order systems and fractional-order controllers. University of Technology Kosice, Mart, 2003.

[16] Saturday E. G. and Promise N. Off-design performance analysis of gas turbines. Global Journal of Engineering and Technology Advances (GJETA), 2020, 04(02), 001-010

[17] Vilău R., Lespezeanu I., Singureanu M. Considerations regarding the influence of inappropriate electronic throttle unit operation on pollutant emissions of internal combustion engines. 5th International Scientific Conference SEA-CONF 2019, IOP Conf. Series: Journal of Physics: Conf. Series 1297 (2019) 012032, IOP Publishing, doi:10.1088/1742-6596/1297/1/012032 